\title{
Investigating the effect of IncRNA HOTAIR on apoptosis induced by myocardial ischemia-reperfusion injury
}

\author{
JIJING FANG ${ }^{1}$, WEIHONG ZHENG ${ }^{2}$, PENGFEI $\mathrm{HU}^{3}$ and JIALE WU ${ }^{4}$ \\ ${ }^{1}$ Department of Rehabilitation Medicine, The First People's Hospital of Tonglu, Tonglu County, Hangzhou, Zhejiang 311500; \\ ${ }^{2}$ School of Life Science, Huzhou University, Huzhou, Zhejiang 313000; ${ }^{3}$ Department of Cardiology, \\ The Second Affiliated Hospital of Zhejiang Chinese Medical University, Hangzhou, Zhejiang 310005; \\ ${ }^{4}$ Department of Geratology, Hangzhou Hospital of Traditional Chinese Medicine, Hangzhou, Zhejiang 310007, P.R. China
}

Received March 9, 2020; Accepted October 30, 2020

DOI: $10.3892 / \mathrm{mmr} .2020 .11808$

\begin{abstract}
The present study aimed to investigate the effect of the long non-coding ribonucleic acid (lncRNA) HOX transcript antisense intergenic RNA (HOTAIR) on apoptosis induced by ischemia-reperfusion injury. Differential lncRNAs in myocardial ischemia rats were screened by a lncRNA microarray and the expression levels of lncRNA HOTAIR and microRNA (miR)-130a-3p were analyzed using reverse transcription-quantitative polymerase chain reaction in hypoxia-induced cardiomyocytes. The mechanism of lncRNA HOTAIR in cardiotoxicity was investigated using cell transfection, lncRNA knockdown, Cell Counting Kit-8, flow cytometry, western blotting, dual luciferase reporter assays and RNA immunoprecipitation. The expression level of lncRNA HOTAIR was significantly downregulated in the ischemic myocardium of rats. Overexpression of HOTAIR in H9c2 (rat cardiomyocyte line) cells could inhibit the apoptosis induced by $\mathrm{H} 2 \mathrm{O} 2$. A direct interaction was found between HOTAIR and miR-130a-3p, and mouse double minute 4 (MDM4) was also found to be a potential target of miR-130a-3p. The overexpression of MDM4 in H9c2 cells transfected with miR-130a-3p mimics increased apoptosis, and miR-130a-3p targeted inhibition of MDM4 promoted H2O2-induced apoptosis of H9c2 cells. Overall, HOTAIR was found to inhibit the apoptosis of $\mathrm{H} 9 \mathrm{c} 2$ cells induced by $\mathrm{H} 2 \mathrm{O} 2$ through the miR-130a-3p/MDM4 axis.
\end{abstract}

\section{Introduction}

Cardiovascular disease is one of the leading causes of human death (1). Acidosis, electrolyte imbalance, hypoxia and

Correspondence to: Professor Jiale Wu, Department of Geratology, Hangzhou Hospital of Traditional Chinese Medicine, 453 Tiyuchang Road, Hangzhou, Zhejiang 310007, P.R. China

E-mail:wujiale1227@126.com

Key words: long non-coding RNA, HOX transcript antisense intergenic RNA, microRNA-130a-3p, mouse double minute 4, myocardial ischemia-reperfusion injury ischemia can cause myocardial cell damage, vascular remodeling, ventricular dysfunction and even death. Cardiomyocyte apoptosis or programmed cell death is an important pathological manifestation of ischemia-reperfusion injury and is the primary cause of cardiac dysfunction (2). Therefore, an in-depth understanding of the mechanism of cardiomyocyte apoptosis is the key to preventing myocardial injury and treating heart disease. At present, multiple apoptosis signaling cascades have been identified in ischemia-reperfusion injury. Recently, non-coding ribonucleic acid (RNA) microRNAs (miRNAs/miRs) and circular RNAs (circRNAs) have been reported to be involved in cardiomyocyte apoptosis. For example, miR-762 targets inhibition of NADH dehydrogenase subunit 2, which thereby inhibits cardiomyocyte apoptosis (3). Knockdown of mouse cardiomyocytes and cardiac tissue circNCX1 promotes the targeted inhibition of cell death-inducing p53-target protein 1 by miR-133a-3p, which inhibits apoptosis and attenuates ischemia-reperfusion injury (4). However, the molecular mechanism of cardiomyocyte apoptosis at the RNA expression level needs further study. In addition, long non-coding RNAs (lncRNAs) have an important role in a number of biological activities, such as epigenetic regulation, cell cycle regulation and cell differentiation regulation (5), but their role in myocardial injury should be explored further.

lncRNAs are non-coding RNA molecules that are $>200$ nucleotides in length. They have a mRNA-like structure. After splicing, they have polyA tail and promoter structure. They participate in various important regulatory processes, such as $\mathrm{X}$ chromosome silencing, genomic imprinting and chromatin modification, transcriptional activation, transcriptional interference and intranuclear transport (6-8). Furthermore, IncRNAs also have a role in the development of cancer, Alzheimer's disease and neurological diseases $(9,10)$. lncRNAs act as a sponge to adsorb miRNAs and regulate target gene expression. lncRNA AK038897 adsorbs miR-26a-5p via its role as a competing endogenous RNA to promote the expression of death-associated protein kinase 1 and aggravate cerebral ischemia/reperfusion injury (11). RNA-Seq data has revealed that the heart contains abundant lncRNAs. The differential expression of lncRNAs in cardiac diseases suggests that there may be a regulatory relationship 
between IncRNAs and cardiovascular diseases. For example, lncCAREL is significantly upregulated in neonatal rat cardiomyocytes that have lost the ability to divide (12), furthermore, knockdown of lncCPR can promote cardiomyocyte proliferation (13). The lncRNA 2810403D21Rik/Mirf is known to promote ischemia-induced cardiomyocyte apoptosis (14). However, the functions and molecular mechanisms of cardiac lncRNAs remain unclear. Therefore, the role of lncRNAs in heart disease, especially ischemic heart disease, should be explored further. The purpose of the present study was to investigate the role of lncRNA HOX transcript antisense intergenic RNA (HOTAIR) in ischemic myocardial injury and to explore its regulatory mechanism in cardiomyocyte apoptosis.

\section{Materials and methods}

Cell culture. Rat $\mathrm{H} 9 \mathrm{c} 2$ cells (American Type Culture Collection) were cultured in Dulbecco's modified Eagle's medium (Corning Inc.) containing 10\% fetal bovine serum (cat. no. 10099141; Gibco; Thermo Fisher Scientific, Inc.). The cells were incubated at $37^{\circ} \mathrm{C}$ in a humidified atmosphere containing $5 \% \mathrm{CO}_{2}$. To initiate oxidative stress, $\mathrm{H} 9 \mathrm{c} 2$ cells were exposed to $\mathrm{H}_{2} \mathrm{O}_{2}(0-100 \mu \mathrm{M})$ for the indicated times at $37^{\circ} \mathrm{C}$.

Experimental animals. All rat experiments conformed to the National Institutes of Health Guidelines on the Use of Laboratory Animals and was approved by The First People's Hospital of Tonglu (Hangzhou, China). A total of 18 adult male Sprague-Dawley (SD) rats at 8-10 weeks of age were purchased from Charles River Laboratories, Inc., three were used to establish a myocardial ischemia-reperfusion (MI/R) injury model. The MI/R model was established as previously described (15). Briefly, SD rats were intubated and artificially ventilated with a rodent ventilator under anesthesia with $10 \%$ chloral hydrate $(300 \mathrm{mg} / \mathrm{kg}$, intraperitoneally). Symptoms of peritonitis in the rats, such as abdominal muscle tension, were checked. An electrocardiogram (ECG) was recorded following subcutaneous placement of electrodes and connection to an electrocardiograph. Coronary artery ligation was achieved with a plastic snare fixed onto the left anterior descending (LAD) coronary artery. A 6-0 silk suture was passed underneath the LAD (2-3 mm inferior to the left auricle) and tied. Following $30 \mathrm{~min}$ of ischemia, the plastic snare was removed and the myocardium was reperfused for $180 \mathrm{~min}$.

Microarray. Kangchen Biotech Co., Ltd., performed the microarray in which six samples (three samples for the MI group and three for the control group) were used for lncRNA microarray analysis by Agilent Array (Agilent Technologies, Inc.). Sample preparation and microarray hybridization were performed in accordance with the manufacturer's standard protocols. Briefly, the total RNA from myocardial tissues of rats was extracted using TRIzol ${ }^{\circledR}$ (Invitrogen; Thermo Fisher Scientific, Inc.), and the purity and integrity of RNA were detected. After hybridization, the different fluorescence intensity of IncRNA was obtained by chip hybridization, and the fluorescence intensity values were obtained by image scanning. The differently expressed lncRNAs with $\mathrm{P}<0.05$ and a fold-change value $>2$ were subsequently selected.
Cell Counting Kit-8 (CCK-8) assay. The H9c2 cells were seeded in 96 -well plates at $1 \times 10^{4}$ cells per well. A CCK-8 (cat. no. HY-K0301; MedChemExpress) was used to detect the viability of cells in accordance with the manufacturer's instructions. The absorbance was measured at $450 \mathrm{~nm}$.

$R N A$ extraction and reverse transcription-quantitative polymerase chain reaction $(R T-q P C R)$. Total RNA was isolated from the cultured cells using TRIzol ${ }^{\circledR}$ reagent (Takara Biotechnology Co., Ltd.), according to the supplier's instructions. The PrimeScript RT Master Mix (Toyobo Life Science) was used to synthesize cDNA from the extracted RNA at $37^{\circ} \mathrm{C}$ for $15 \mathrm{~min}$, $50^{\circ} \mathrm{C} 5 \mathrm{~min}$ and $98^{\circ} \mathrm{C} 5 \mathrm{~min}$. SYBR Premix Ex Taq (Takara Biotechnology Co., Ltd.) was used to perform the RT-qPCR, and GAPDH was the internal control. The primers used were synthesized by Shangya Biotechnology. The primer sequence was as follows: HOTAIR forward (Fw), 5'-CCTTATAAGCTCATCG GAGCA-3' and reverse (Rv), 5'-CATTTCTGGGTGGTTCC TTT-3'; rno-miR-130a-3p Fw, 5'-CGCCAGGGTTTTCCCA GTCACGACCAGTGCAATGTTAAAAGGGCAT-3' and Rv, 5'-CGCGAGGAGAGAATTAATACGACTCAGTATACGCGA TGCCCT-3'; mouse double minute 4 (MDM4) Fw, 5'-CTCAGT GTCAACATCTGACAG-3' and Rv, 5'-CATATGCTGCTCC TGCTGATC-3'; GAPDH Fw, 5'-GGAGCGAGATCCCTCCAA AAT-3' and Rv, 5'-GGCTGTTGTCATACTTCTCATGG-3'; U6 Fw, 5'-GCGCGTCGTGAAGCGTTC-3' and Rv, 5'-GTGCAGG GTCCGAGGT-3'. The reaction conditions were as follows: Predenaturation at $95^{\circ} \mathrm{C}$ for $5 \mathrm{~min}$, followed by 35 cycles of denaturation at $94^{\circ} \mathrm{C}$ for $45 \mathrm{sec}$, annealing at $53-56^{\circ} \mathrm{C}$ for $45 \mathrm{sec}$ and an extension at $72^{\circ} \mathrm{C}$ for $45 \mathrm{sec}$. PCR was carried out using the ABI PRISM ${ }^{\circledR} 7500$ System (Applied Biosystems; Thermo Fisher Scientific, Inc.). The expression of RNA relative to GAPDH was calculated using the $2^{-\Delta \Delta \mathrm{Cq}}$ method (13).

Construction of the plasmid and cell transfection. The HOTAIR, MDM4-wild-type (WT), MDM4-mutant (MT) and rno-miR-130a-3p sequences were designed and synthesized by Shangya, which were further subcloned into pcDNA3.1 (Invitrogen; Thermo Fisher Scientific, Inc.). The pcDNA3.1 vector was used as control. Lipofectamine ${ }^{\circledR} 3000$ (Invitrogen; Thermo Fisher Scientific, Inc.) was used to transfect or co-transfect the plasmids (500 ng pcDNA3.1-vector, $500 \mathrm{ng}$ HOTAIR, 600 ng MDM4-WT, 600 ng MDM4-MT and 500 ng rno-miR-130a-3p) into the H9c2 cells at $60 \%$ confluency in 6-well plates. After 48-72 h, the transfected cells were used for the subsequent experiments.

Western blotting. The cells were washed with PBS and incubated on ice in 1X RIPA buffer (Beyotime Institute of Biotechnology), containing 1X PhosSTOP protease inhibitor (Shanghai Yeasen Biotechnology Co., Ltd.) and $1 \mathrm{X}$ complete Protease Inhibitor Cocktail (Shanghai Yeasen Biotechnology Co., Ltd.) for $30 \mathrm{~min}$. The lysates were pre-cleared by centrifugation at $12,000 \mathrm{x}$ g for $10 \mathrm{~min}$ at $4^{\circ} \mathrm{C}$, and the protein was quantified using the Yeasen Protein Assay Kit (Shanghai Yeasen Biotechnology Co., Ltd.). Then, protein lysate $(20 \mu \mathrm{g})$ was resolved via SDS-PAGE on $10 \%$ gel, and subsequently transferred to a PVDF membrane (Bio-Rad Laboratories, Inc.). The blots were blocked using $5 \%$ skimmed milk for $1 \mathrm{~h}$ at room temperature, and then 
incubated with the primary antibody overnight at $4{ }^{\circ} \mathrm{C}$. Then, the blots were washed and incubated with secondary antibody for $2 \mathrm{~h}$ at room temperature, followed by washing and visualization of the protein bands using an ECL chemiluminescence kit (Hangzhou Fude Chemical Co., Ltd.). GAPDH was used as the loading control. The primary antibodies used were as follows: Bax (cat. no.2772; 1:1,000; CST Biological Reagents Co., Ltd.), Bcl-2 (cat. no. 2764; 1:1,000; CST Biological Reagents Co., Ltd.), MDM4 (cat. no. A300-287A; 1:1,000; Bethyl Laboratories, Inc.) and GAPDH (cat. no. ab128915; 1:2,500; Abcam). The secondary antibodies used were as follows: Anti-rabbit (cat. no. 7074; 1:10,000; CST Biological Reagents Co., Ltd.) and anti-mouse (cat. no. 6789; 1:10,000; Abcam).

Luciferase reporter gene assay. The $\mathrm{H} 9 \mathrm{c} 2$ cells $\left(5 \times 10^{4}\right)$ were seeded in 96 -well plates and incubated at $37^{\circ} \mathrm{C}$ for $24 \mathrm{~h}$. A HOTAIR 3'-untranslated region (UTR)-Luc vector with WT or MT plasmids was constructed at the miR-130a-3p binding site of the 3'UTR region of IncRNA HOTAIR. A MDM4 3'-UTR-Luc vector with a WT or MT gene was constructed at the miR-130a-3p binding site of the 3'UTR region of the MDM4. The plasmids were co-transfected with the H9c2 cells using Lipofectamine ${ }^{\circledR} 3000$, harvested after $48 \mathrm{~h}$, and the luciferase activity was measured by a dual luciferase assay system (Promega Corporation). Firefly luciferase activity was normalized to Renilla luciferase activity.

Short hairpin (sh)RNA vectors. The sense and antisense oligonucleotides of the shRNA HOTAIR (5'-AAAUCCAGAA CCCUCUGACAUUUGC-3') were synthesized and cloned into the $\mathrm{pENTR}^{\mathrm{TM}} / \mathrm{U} 6$ vector (Invitrogen; Thermo Fisher Scientific, Inc.). H9c2 cells $\left(5 \times 10^{4}\right)$ were transfected with $1 \mu \mathrm{g}$ shRNA using Lipofectamine ${ }^{\circledR} 3000$ (Invitrogen; Thermo Fisher Scientific, Inc.,), according to the manufacturer's protocol. After $48 \mathrm{~h}$, the transfected cells were used for subsequent experiments.

Flow cytometry. Early and late apoptotic cells were detected using the Annexin V-FITC/propidium iodide Apoptosis Detection Kit (BD Pharmingen; BD Biosciences) after cell treatment. According to the manufacturer's instructions, the stained cells were assayed by flow cytometry (FACSCalibur ${ }^{\mathrm{TM}}$; BD Biosciences). The positive cells were calculated and analyzed using FlowJo software (version 8; Tree Star, Inc.).

RNA immunoprecipitation (RIP). The RIP assay was performed using the Magna RIP ${ }^{\mathrm{TM}}$ RNA-Binding Protein Immunoprecipitation Kit (EMD Millipore), according to the manufacturer's protocols. Briefly, cultured chondrocytes were collected and resuspended in RIP lysis buffer (Beijing Solarbio Science \& Technology Co., Ltd.); then, the cell extracts were incubated with RIP buffer containing magnetic beads conjugated with human anti-Ago2 antibody (EMD Millipore) or mouse immune globulin G (IgG) control (cat. no. ab172730; Abcam) overnight at $4^{\circ} \mathrm{C}$. The next day, the magnetic beads were incubated with $50 \mu \mathrm{g} / \mathrm{ml}$ Proteinase K (cat. no. P2308; Sigma-Aldrich; Merck KGaA) after washing three times. Total RNAs were isolated from the extracts using the TRIzol ${ }^{\circledR} \mathrm{LS}$ reagent (Thermo Fisher Scientific, Inc.). Finally, the relative enrichment of HOTAIR and miR-130a-3p were determined by RT-qPCR analysis.

miRNA regulatory network. StarBase (http://starbase.sysu.edu. $\mathrm{cn} /$ ) and TargetScan (http://www.targetscan.org/) databases were used to explore target mRNAs.

Statistical analysis. Statistical analysis was performed using the GraphPad Prism 7 (GraphPad Software, Inc.). The data are presented as the mean \pm standard deviation. Statistical comparisons were performed using a paired t-test and one-way ANOVA. Following ANOVA, Bonferroni's post hoc test was performed. $\mathrm{P}<0.05$ was considered to indicate a statistically significant difference.

\section{Results}

Downregulation of HOTAIR in the ischemic myocardium mouse heart tissue and $\mathrm{H} 2 \mathrm{O} 2$-treated $\mathrm{H} 9 \mathrm{c} 2$ cells. Initially, the cardiac differential lncRNA in MI rats was screened by lncRNA chip technology. It was found that HOTAIR expression levels were downregulated in ischemic myocardium rat heart tissue (Fig. 1A). Excessive reactive oxygen species are produced under cardiac pathological conditions, and $\mathrm{H}_{2} \mathrm{O}_{2}$ is often used to mimic the induction of reactive oxygen species-induced apoptosis in MI in vitro (16). To investigate the role of HOTAIR in ROS-induced cardiomyocyte apoptosis, H9c2 cells were treated with $100 \mu \mathrm{M} \mathrm{H}_{2} \mathrm{O}_{2}$ at different time-points $(0,3,6$ and $12 \mathrm{~h}$ ) and RT-qPCR was used to determine the expression levels of HOTAIR. The present study found that HOTAIR expression significantly decreased with prolonged $\mathrm{H}_{2} \mathrm{O}_{2}$ treatment time (Fig. 1B). Similarly, H9c2 cells were treated with different concentrations of $\mathrm{H}_{2} \mathrm{O}_{2}$, and the expression level of HOTAIR was significantly reduced (Fig. 1C). Further experiments found that HOTAIR was significantly downregulated in mouse heart tissue with myocardial infarction (Fig. 1D). These results suggested that HOTAIR could be associated with reactive oxygen species-induced cardiomyocyte injury.

HOTAIR inhibits $\mathrm{H}_{2} \mathrm{O}_{2}$-induced cardiomyocyte apoptosis. To further investigate the role of HOTAIR in $\mathrm{H}_{2} \mathrm{O}_{2}$-induced cardiomyocyte apoptosis, a HOTAIR overexpression plasmid was successfully constructed and transfected into cells (Fig. 2A). HOTAIR significantly increased $\mathrm{H} 9 \mathrm{c} 2$ cell viability following $\mathrm{H}_{2} \mathrm{O}_{2}$ treatment and reduced apoptosis (Fig. 2B and C). Western blot analysis showed that HOTAIR promoted the expression of the anti-apoptotic protein Bcl-2 in $\mathrm{H} 9 \mathrm{c} 2$ cells and inhibited the expression of the proapoptotic protein Bax (Fig. 2D). These results indicated that HOTAIR inhibited $\mathrm{H}_{2} \mathrm{O}_{2}$-induced cardiomyocyte apoptosis.

HOTAIR downregulates miR-130a-3p expression levels. The StarBase database was used to predict that HOTAIR has a binding site with miR-130a-3p (Fig. 3A). To determine the regulatory relationship between HOTAIR and miR-130a-3p, HOTAIR-WT luciferase activity was found to be reduced in H9c2 cells co-transfected with HOTAIR-WT and miR-130a-3p mimics by dual luciferase reporter assay (Fig. 3B). The results of RIP showed that HOTAIR-WT interacted directly with miR-130a-3p (Fig. 3C). As shown in Fig. 3D and E, 

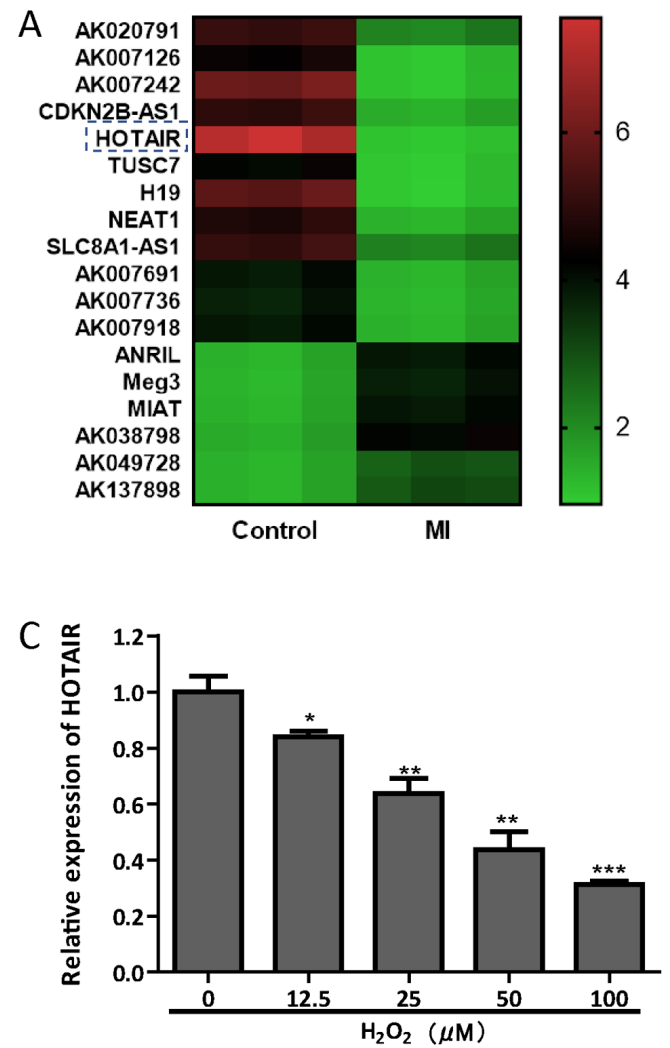

B
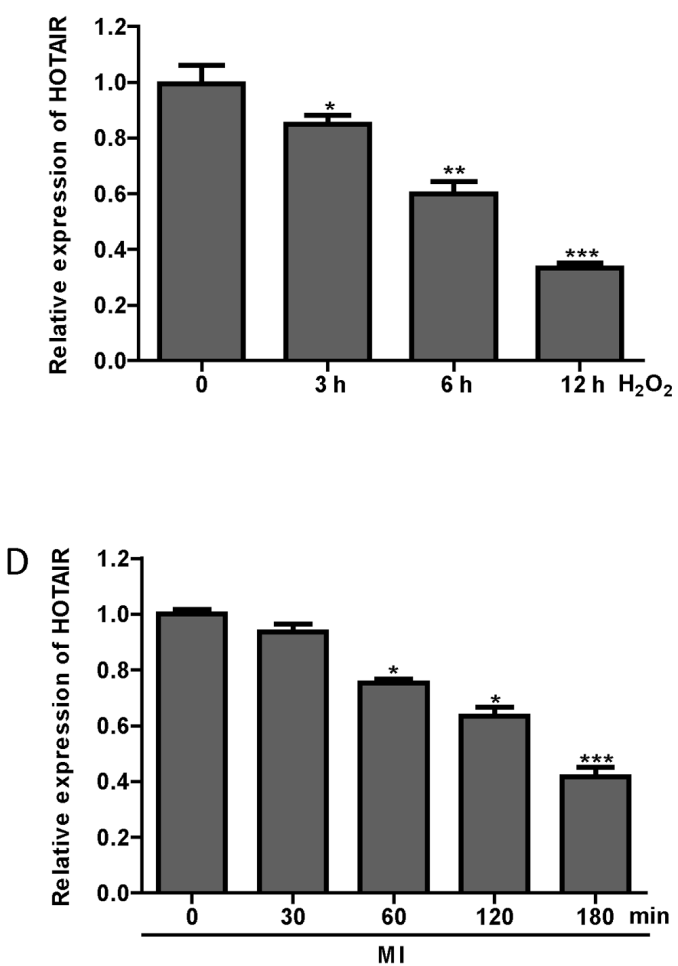

Figure 1. Downregulation of HOTAIR in the ischemic myocardium mouse heart tissue and $\mathrm{H}_{2} \mathrm{O}_{2}$-treated $\mathrm{H} 9 \mathrm{c} 2$ cells. (A) 1ncRNA microarray was used to screen for differential lncRNAs in MI rats. (B) H9c2 cells were treated with $100 \mu \mathrm{M} \mathrm{H}_{2} \mathrm{O}_{2}$ at different time-points (0, 3, 6 and 12 h), and HOTAIR expression levels were detected by RT-qPCR. (C) After H9c2 cells were treated with $0-100 \mu \mathrm{M} \mathrm{H}_{2} \mathrm{O}_{2}$ for $12 \mathrm{~h}$, RT-qPCR was used to detect the expression of HOTAIR. (D) After MI (0, 30, 60, 120 and $180 \mathrm{~min})$ in rats, RT-qPCR was used to detect the expression of HOTAIR in cardiac tissue. ${ }^{*} \mathrm{P}<0.05$, ${ }^{* *} \mathrm{P}<0.01$ and ${ }^{* * *} \mathrm{P}<0.001$ vs. control group. MI, myocardial ischemia; lncRNA, long non-coding RNA; RT-qPCR; reverse transcription-quantitative PCR; HOTAIR, HOX transcript antisense intergenic RNA.

the expression of miR-130a-3p was decreased following overexpression of HOTAIR in H9c2 cells, whereas when the expression of HOTAIR was downregulated, the expression of miR-130a-3p was increased. In addition, miR-130a-3p was found to be significantly elevated in ischemic myocardium mouse heart tissue and $\mathrm{H}_{2} \mathrm{O}_{2}$-treated $\mathrm{H} 9 \mathrm{c} 2$ cells (Fig. 3F and $\mathrm{G}$ ). The results indicated that HOTAIR can function as an miRNA sponge to adsorb miR-130a-3p.

HOTAIR downregulates miR-130a-3p expression and reduces $\mathrm{H}_{2} \mathrm{O}_{2}$-induced apoptosis of $\mathrm{H} 9 \mathrm{c} 2$ cells. In order to confirm that HOTAIR downregulates miR-130a-3p expression and affects $\mathrm{H}_{2} \mathrm{O}_{2}$-induced apoptosis of $\mathrm{H} 9 \mathrm{c} 2$ cells, miR-130a-3p mimics were synthesized to transfect $\mathrm{H} 9 \mathrm{c} 2$ cells, which was successful and miR-130a-3p expression significantly increased (Fig. 4A). Then, $\mathrm{H} 9 \mathrm{c} 2$ cells transfected with the miR-130a-3p mimic were treated with $\mathrm{H}_{2} \mathrm{O}_{2}$, which significantly decreased cell viability and increased the proportion of cells undergoing apoptosis. When the H9c2 cells were co-transfected with miR-130a-3p mimics and HOTAIR overexpression vector, the cell viability increased and the cell apoptosis decreased (Fig. 4B and C). Similarly, miR-130a-3p mimics were found to inhibit the expression of $\mathrm{Bcl}-2$ protein and promote the expression of Bax protein, whereas H9c2 cells co-transfected with HOTAIR overexpression vector and miR-130a-3p mimics showed increased expression of Bcl-2 and decreased expression of Bax (Fig. 4D). These results indicated that HOTAIR could reduce the apoptosis of $\mathrm{H} 9 \mathrm{c} 2$ cells induced by $\mathrm{H}_{2} \mathrm{O}_{2}$ by downregulating the expression of miR-130a-3p.

miR-130a-3p targets the inhibition of MDM4 and promotes $\mathrm{H}_{2} \mathrm{O}_{2}$-induced $\mathrm{H} 9 \mathrm{c} 2$ cell apoptosis. In order to elucidate the molecular mechanism by which miR-130a-3p regulates apoptosis, TargetScan and RNA hybrids were used to analyze potential target genes. MDM4 was revealed to be a potential target gene of miR-130a-3p (Fig. 5A). MDM4 is known to be an important inhibitor of apoptosis (15). However, whether MDM4 participates in cardiomyocyte apoptosis needs to be explored further. The expression of MDM4 protein was found to be decreased in the heart tissue of rats with $\mathrm{MI}$ and in $\mathrm{H} 9 \mathrm{c} 2$ cells treated with $\mathrm{H}_{2} \mathrm{O}_{2}$ (Fig. $5 \mathrm{~B}$ and C). Luciferase reporter assays showed that miR-130a-3p mimics significantly reduced the activity of MDM4-WT luciferase (Fig. 5D). The MDM4 protein expression of $\mathrm{H} 9 \mathrm{c} 2$ cells treated with miR-130a-3p mimics decreased (Fig. 5E). Whereas, when $\mathrm{H} 9 \mathrm{c} 2$ cells were treated with miR-130a-3p inhibitor, which successfully knocked down miR-130a-3p expression (Fig. 5F), MDM4 protein expression increased (Fig. 5G). In addition, overexpression of MDM4 in H9c2 cells (Fig. 5H) treated with $\mathrm{H}_{2} \mathrm{O}_{2}$ resulted in increased cell viability, decreased apoptosis, increased Bcl-2 protein expression and decreased Bax protein expression. Transfection of miR-130a-3p mimics into H9c2 cells that were overexpressing MDM4 resulted in decreased cell viability, increased apoptosis, decreased $\mathrm{Bcl}-2$ protein 

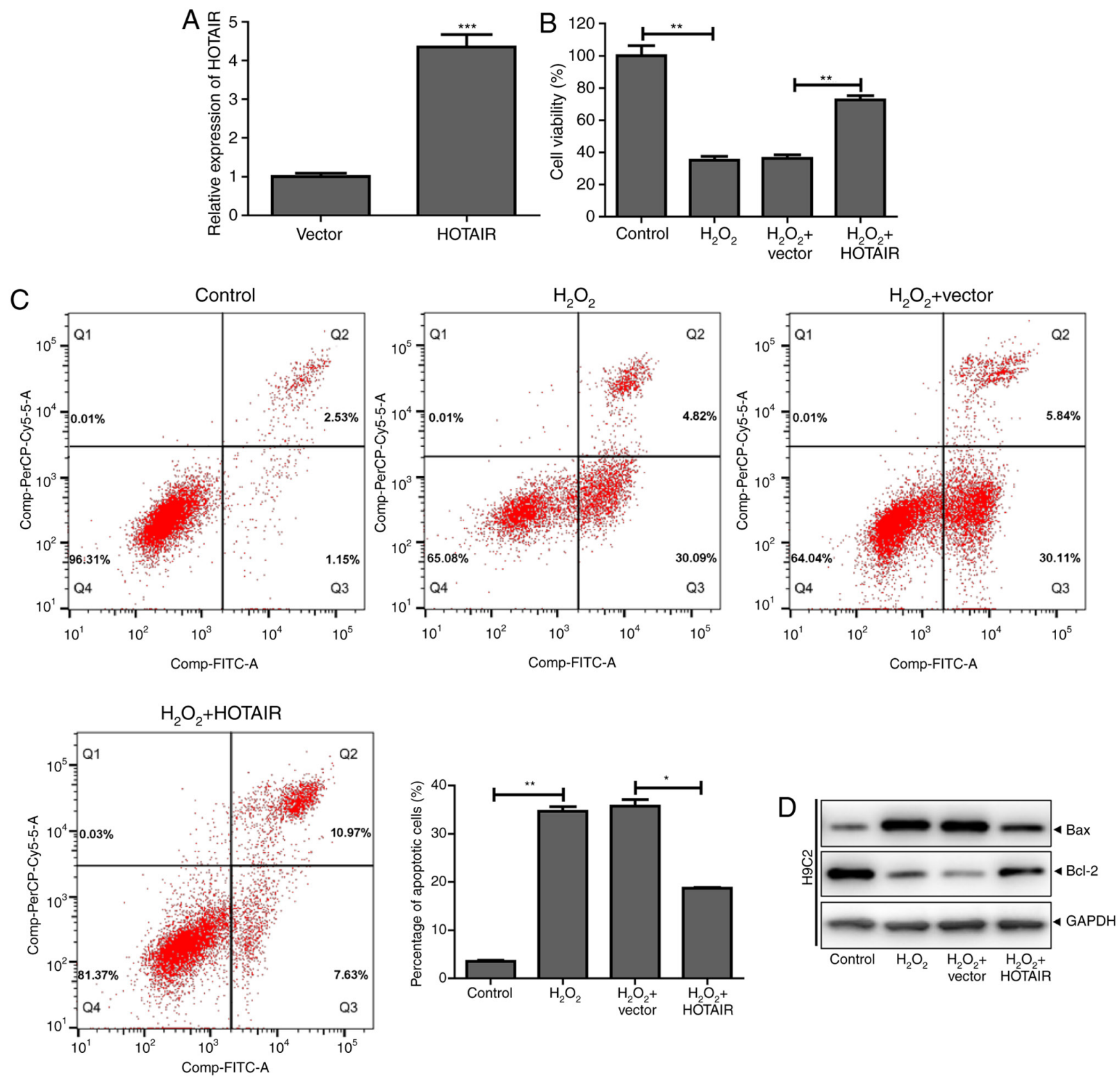

Figure 2. HOTAIR inhibits $\mathrm{H}_{2} \mathrm{O}_{2}$-induced cardiomyocyte apoptosis. (A) HOTAIR overexpression plasmid and control plasmid were transfected into H9c2 cells for $48 \mathrm{~h}$, and HOTAIR expression levels were detected by reverse transcription-quantitative PCR. (B) HOTAIR overexpression plasmid and control plasmid were transfected into $\mathrm{H} 9 \mathrm{c} 2$ cells for $48 \mathrm{~h}, \mathrm{H} 9 \mathrm{c} 2$ cardiomyocytes were treated with $\mathrm{H}_{2} \mathrm{O}_{2}$ for $12 \mathrm{~h}$, and a Cell Counting Kit-8 assay was used to detect cell viability. (C) HOTAIR overexpression plasmid and control plasmid were transfected into $\mathrm{H} 9 \mathrm{c} 2$ cells for $48 \mathrm{~h}, \mathrm{H} 9 \mathrm{C} 2$ cardiomyocytes were treated with $\mathrm{H}_{2} \mathrm{O}_{2}$ for $12 \mathrm{~h}$, and the proportion of apoptosis was detected by flow cytometry. (D) HOTAIR overexpression plasmid and control plasmid were transfected into H9c2 cells for $48 \mathrm{~h}, \mathrm{H} 9 \mathrm{c} 2$ cardiomyocytes were treated with $\mathrm{H}_{2} \mathrm{O}_{2}$ for $12 \mathrm{~h}$, and Bcl- 2 and Bax protein expression were detected by western blotting. " $\mathrm{P}<0.05$, ${ }^{* *} \mathrm{P}<0.01$ and ${ }^{* * *} \mathrm{P}<0.001$ vs. vector group or as indicated. HOTAIR, HOX transcript antisense intergenic RNA.

expression and increased Bax protein expression (Fig. 5I-K). The results showed that miR-130a-3p could inhibit MDM4 to promote $\mathrm{H}_{2} \mathrm{O}_{2}$-induced apoptosis of $\mathrm{H} 9 \mathrm{c} 2$ cells.

HOTAIR inhibits $\mathrm{H}_{2} \mathrm{O}_{2}$-induced $\mathrm{H} 9 \mathrm{c} 2$ cell apoptosis via the miR-130a-3p/MDM4 axis. The present study sought to determine whether HOTAIR regulated $\mathrm{H}_{2} \mathrm{O}_{2}$-induced $\mathrm{H} 9 \mathrm{c} 2$ cell apoptosis via the miR-130a-3p/MDM4 axis. It was revealed that HOTAIR increased MDM4-MT luciferase activity by inhibiting miR-130a-3p (Fig. 6A). Subsequently, HOTAIR was found to promote MDM4 expression, whereas depleting HOTAIR expression inhibited MDM4 expression (Fig. 6B and C). Further assays indicated that miR-130a-3p mimics inhibited HOTAIR-induced MDM4 expression, whereas the miR-130a-3p inhibitor restored MDM4 reduction due to HOTAIR knockdown (Fig. 6D and E). MDM4 expression was successfully knocked down in H92c cells using shMDM4 (Fig. 6F). Knockdown of MDM4 in H9c2 cells overexpressing HOTAIR, resulted in decreased cell viability, increased apoptosis, decreased expression of $\mathrm{Bcl}-2$ protein and increased expression of Bax protein (Fig. 6G-I). These results indicated that HOTAIR inhibited $\mathrm{H}_{2} \mathrm{O}_{2}$-induced apoptosis of $\mathrm{H} 9 \mathrm{c} 2$ cells via the miR-130a-3p/MDM4 axis.

\section{Discussion}

Currently, patients worldwide suffer from MI $(17,18)$. However, $\mathrm{MI} / \mathrm{R}$ injury is a difficult problem for doctors. At present, the 


\section{A HOTAIR $5^{\prime}$...TCATATACTAGGCTGATAGCACTT \\ rno-miR-130a-3p $3^{\prime} \quad \underset{\|}{\mid}|||||| \mid$}
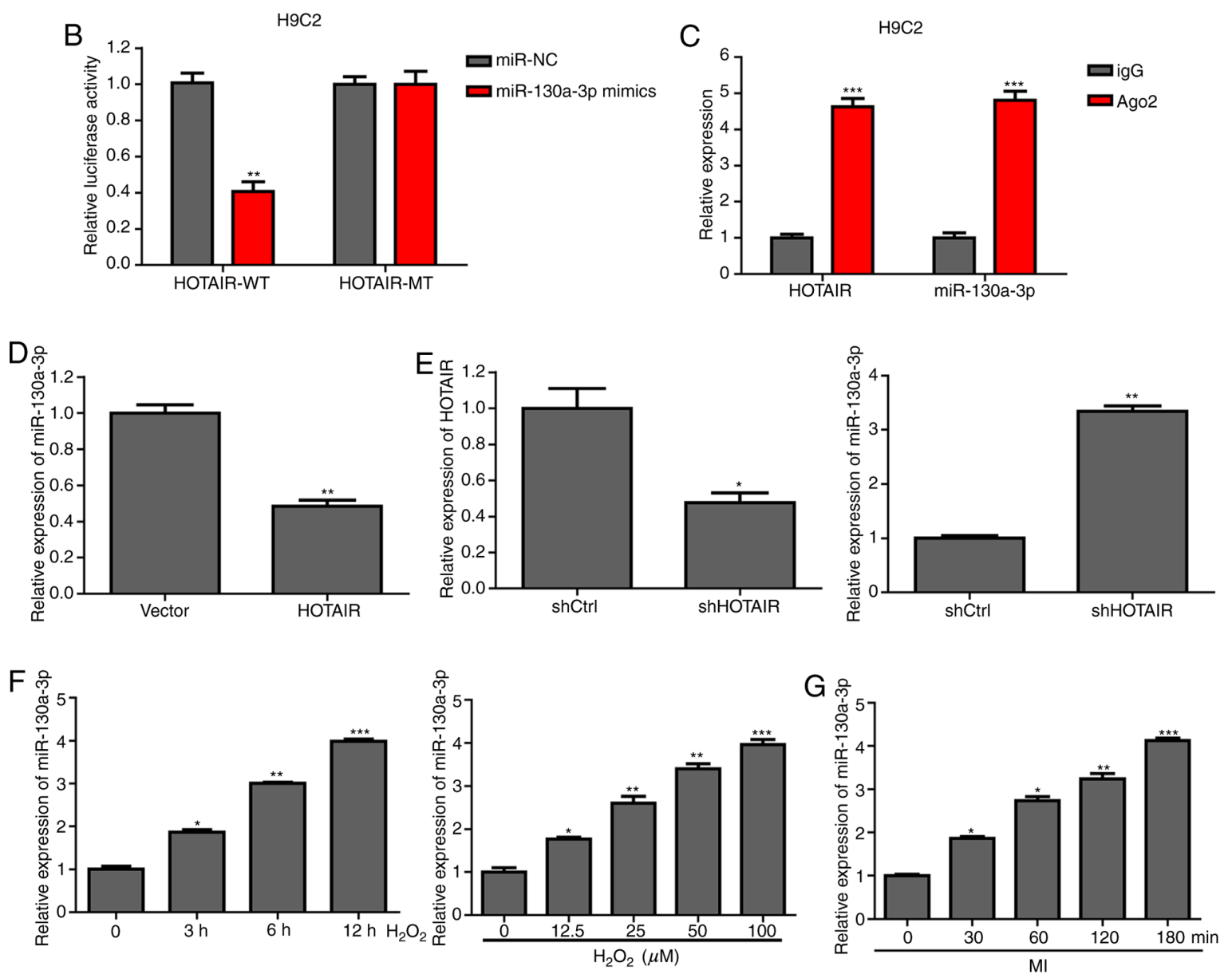

Figure 3. HOTAIR downregulates miR-130a-3p expression levels. (A) Bioinformatics analysis was used to predict the binding site of HOTAIR to miR-130a-3p. (B) The luciferase reporter gene detection system was used to detect luciferase activity after co-transfection of HOTAIR-WT or -MT reporter plasmids with scramble or miR-130a-3 mimics for $48 \mathrm{~h}$, according to the manufacturer's instructions. (C) H9c2 cells were collected, lysed and incubated with magnetic beads that contained Ago2 or IgG antibody, and HOTAIR and miR-130a-3p expression levels were detected by RT-qPCR. (D) HOTAIR overexpression plasmid or control plasmid was transfected into H9c2 cells, and miR-130a-3p expression levels were detected by RT-qPCR. (E) shHOTAIR or shControl was transfected into H9c2 cells, and miR-130a-3p expression levels were detected by RT-qPCR. (F) H9c2 cells were treated with $100 \mu \mathrm{M} \mathrm{H}_{2} \mathrm{O}_{2}$ at different time-points $(0,3,6$ and $12 \mathrm{~h}$ ), and RT-qPCR was performed to detect miR-130a-3p expression. (G) After MI (0, 30, 60, 120 and $180 \mathrm{~min}$ ), the expression of miR-130a-3p in cardiac tissue was determined using RT-qPCR. ${ }^{*} \mathrm{P}<0.05,{ }^{* *} \mathrm{P}<0.01$ and ${ }^{* * * *} \mathrm{P}<0.001$ vs. control group. MI, myocardial ischemia; RT-qPCR, reverse transcription-quantitative PCR; Ago2, Argonaute 2; IgG, Immunoglobin G; miR, microRNA; HOTAIR, HOX transcript antisense intergenic RNA; WT, wild-type; MT, mutant; sh-, short hairpin RNA; NC, negative control.

treatment of MI/R primarily includes both non-pharmacological and pharmacological treatments (18). To date, the most encouraging measures are ischemic postconditioning, remote ischemic preconditioning, atrial natriuretic peptide, adenosine, cyclosporine and exenatide (18). However, the overall therapeutic effect is not satisfactory, and there are still varying degrees of microvascular dysfunction after treatment $(19,20)$. Therefore, it is necessary to study new drugs and treatment methods to treat MI/R injury.

The present study found that the lncRNA, HOTAIR, was significantly downregulated in ischemic myocardium mouse heart tissues by lncRNA array. H9c2 cells were treated with $\mathrm{H}_{2} \mathrm{O}_{2}$ to simulate reactive oxygen species-induced cardiomyocytes. It was found that HOTAIR expression levels gradually decreased with prolonged $\mathrm{H}_{2} \mathrm{O}_{2}$ treatment time, and HOTAIR was lowly expressed in the heart tissue of rats with myocardial infarction. These results suggested that HOTAIR may be associated with reactive oxygen species-induced cardiomyocyte injury. Overexpression of HOTAIR in H9c2 cells enhanced cell viability and inhibited apoptosis induced by $\mathrm{H}_{2} \mathrm{O}_{2}$.

lncRNAs are localized to the cytoplasm and function as miRNA sponges to downregulate miRNA expression levels. Studies have found that HOTAIR adsorbs miR-519d-3p to inhibit hypoxia-induced cardiomyocyte injury (21). Li et al (22) found that the IncRNA H19 imprinted maternally expressed transcript/miR-675 axis is involved in the regulation of high glucose-induced apoptosis by targeting voltage-dependent anion-selective channel protein 1 . The present study found a direct interaction between HOTAIR-WT and miR-130a-3p by bioinformatics, dual luciferase reporter assay and RIP. The results indicated that HOTAIR could adsorb miR-130a-3p. By overexpressing HOTAIR and miR-130a-3p mimics in H9c2 cells, HOTAIR 

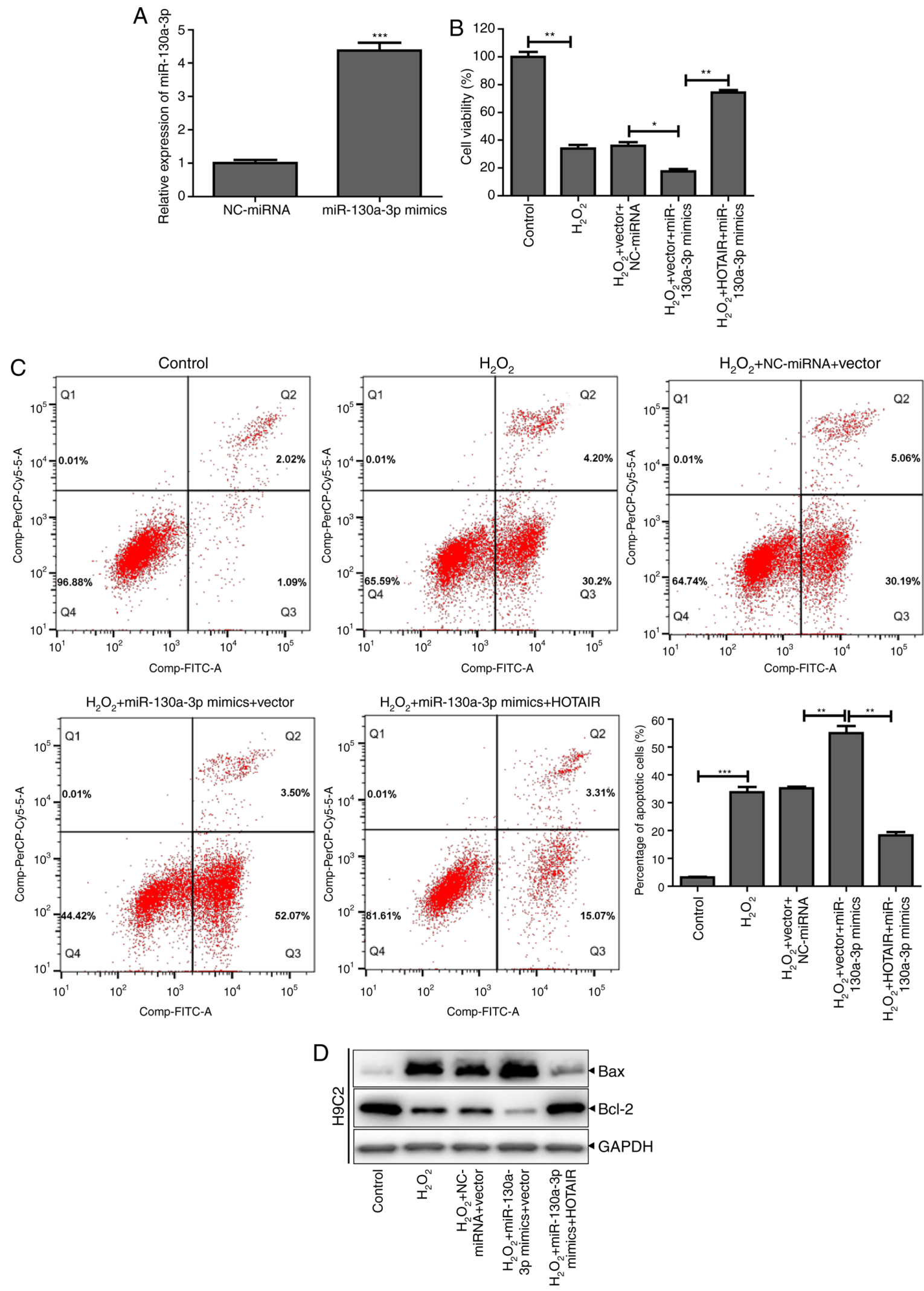

Figure 4. HOTAIR downregulates miR-130a-3p expression and reduces $\mathrm{H}_{2} \mathrm{O}_{2}$-induced apoptosis of $\mathrm{H} 9 \mathrm{c} 2$ cells. (A) Scramble or miR-130a-3p mimics were transfected into H9c2 cells following the manufacturer's instructions. After transfection for $48 \mathrm{~h}$, miR-130a-3p expression levels were detected by reverse transcription-quantitative PCR. (B) Cell Counting Kit- 8 assay was used to detect changes in cell viability. (C) The proportion of apoptosis was detected by flow cytometry. (D) The expression of Bcl-2 and Bax protein was detected by western blotting. ${ }^{*} \mathrm{P}<0.05,{ }^{* *} \mathrm{P}<0.01$ and ${ }^{* * *} \mathrm{P}<0.001$ vs. NC-miRNA or as indicated. miR/miRNA, microRNA; NC, negative control; HOTAIR, HOX transcript antisense intergenic RNA.

downregulated miR-130a-3p expression levels to attenuate $\mathrm{H}_{2} \mathrm{O}_{2}$-induced $\mathrm{H} 9 \mathrm{c} 2$ cell apoptosis.
miR-130a-3p has been found to be associated with apoptosis, for example Wang et al (23) reported that miR-130a-3p 

$\begin{array}{lll}\text { MDM4 } & 5^{\prime} \text {... AGAUGGGUGACGUUUGCACUG... } \\ \text { rno-miR-130a-3p } & 3^{\prime} & \text { UACGgGaAAUUGUACGUGAC }\end{array}$
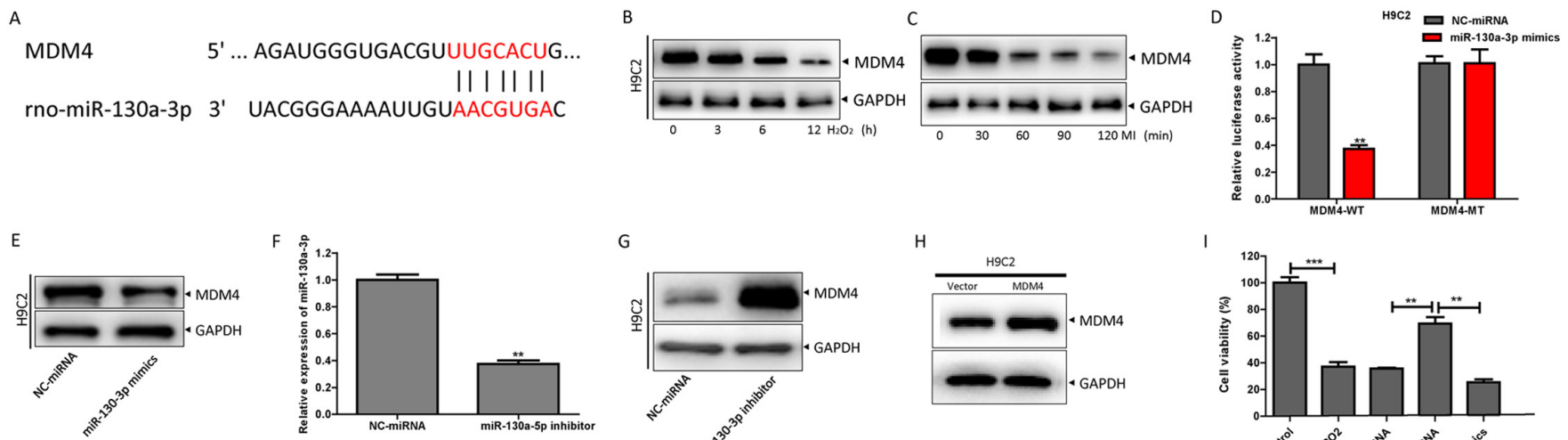

G
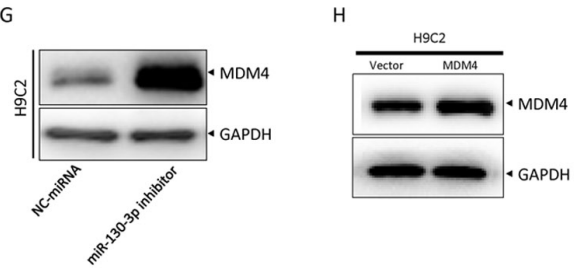

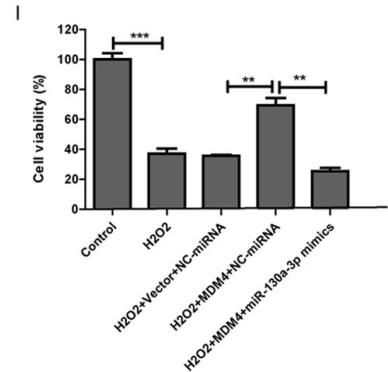

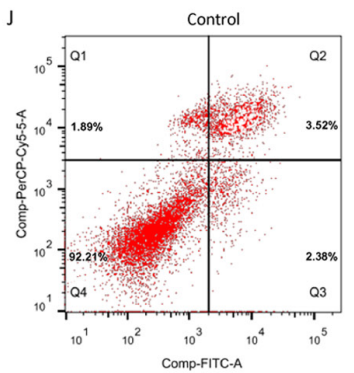
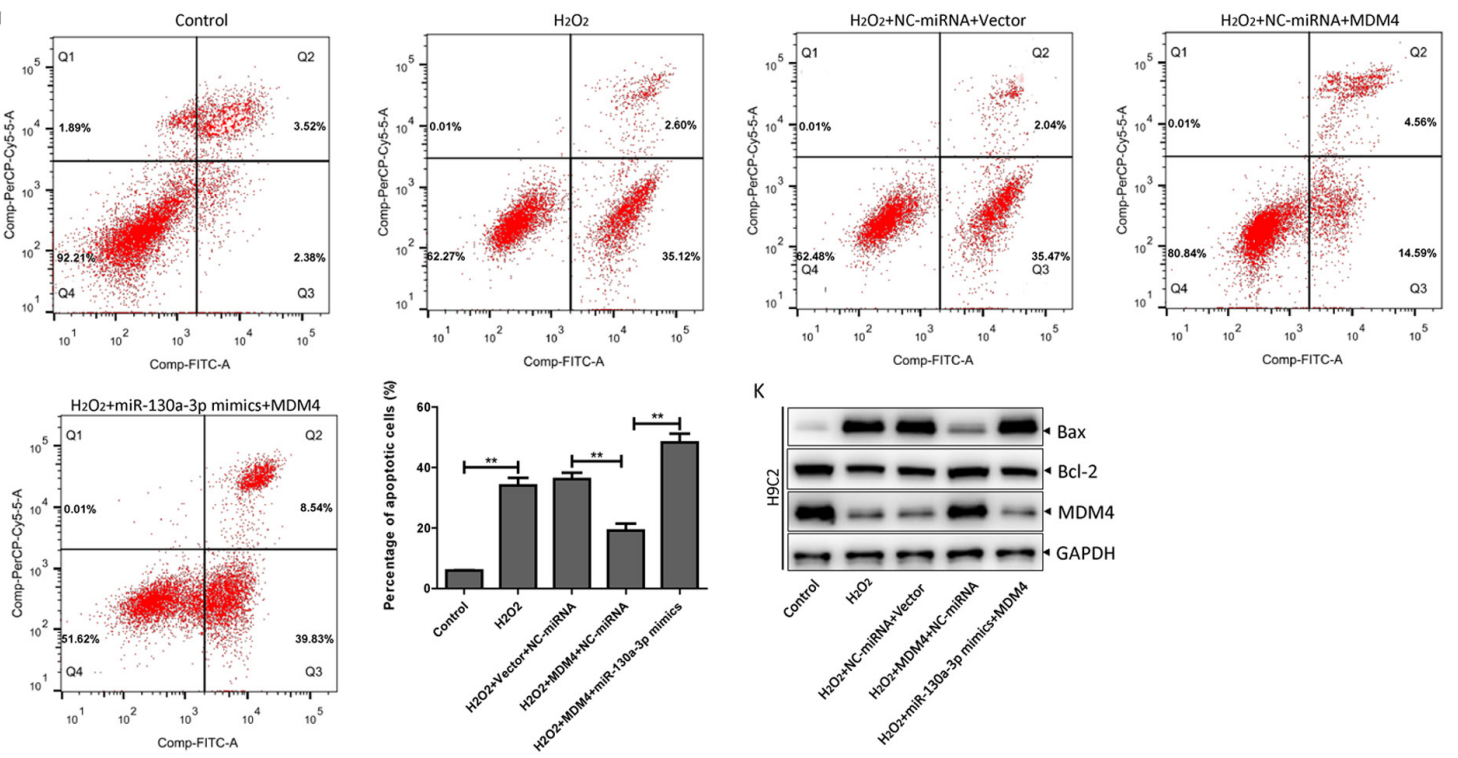

Figure 5. miR-130a-3p targets the inhibition of MDM4 and promotes $\mathrm{H}_{2} \mathrm{O}_{2}$-induced $\mathrm{H} 9 \mathrm{c} 2$ cell apoptosis. (A) TargetScan was used to predict the binding sites of MDM4 and miR-130a-3p. (B) The expression of MDM4 in H9c2 cells treated with $100 \mu \mathrm{m} \mathrm{H}_{2} \mathrm{O}_{2}$ at different time-points $(0,3,6$ and $12 \mathrm{~h})$ was detected by western blotting. (C) After MI (0, 30, 60, 120 and $180 \mathrm{~min})$, the expression of MDM4 was detected by western blotting. (D) The MDM4-WT or -MT reporter plasmids were co-transfected with scramble or miR-130a-3p mimics, respectively, in accordance with the manufacturer's instructions for $48 \mathrm{~h}$, and then the luciferase activity was detected by a luciferase reporter gene detection system. Then, the H9c2 cells were treated with scramble and (E) miR-130a-3p mimics for $48 \mathrm{~h}$, and the expression of MDM4 protein was detected by western blotting. (F) H9c2 cells were successfully transfected with miR-130a-3p inhibitor for $48 \mathrm{~h}$, and $(\mathrm{G})$ the expression of MDM4 protein was detected by western blotting. (H) H9c2 cells were successfully transfected with an MDM4 overexpression vector. (I) According to the manufacturer's instructions, scramble or miR-130a-3p mimics were transfected into H9c2 cells with MDM4 overexpression and control plasmids. After treating with $\mathrm{H}_{2} \mathrm{O}_{2}$ for $12 \mathrm{~h}$, a Cell Counting Kit- 8 assay was used to detect the changes in cell viability. (J) The apoptotic ratio was assessed by flow cytometry. (K) Western blotting was performed to detect the expression of MDM4, Bcl-2 and Bax protein. ${ }^{* *} \mathrm{P}<0.01$ and ${ }^{* * * *} \mathrm{P}<0.001 \mathrm{vs}$. NC-miRNA or as indicated. MDM4, mouse double minute 4; miR/miRNA, microRNA; MI, myocardial ischemia; WT, wild-type; NC, negative control; MT, mutant.

attenuates activation and induces apoptosis of hepatic stellate cells and Chen et al (24) demonstrated that miR-130a-3p promotes apoptosis of nasopharyngeal carcinoma cells. The present study found that MDM4 is a potential target gene of miR-130a-3p through TargetScan analysis and using RNA hybrids. The luciferase reporter assay found that transfection with miR-130a-3p mimics significantly reduced MDM4-WT luciferase activity. Transfection of miR-130a-3p mimics into H9c2 cells overexpressing MDM4 resulted in decreased cell viability and increased apoptosis, which indicated that miR-130a-3p targeted inhibition of MDM4 promoted $\mathrm{H}_{2} \mathrm{O}_{2}$-induced $\mathrm{H} 9 \mathrm{c} 2$ cell apoptosis.

Further studies in the present study showed that miR-130a-3p mimics inhibited HOTAIR-induced MDM4 expression, and that a miR-130a-3p inhibitor restored the reduction of MDM4 expression caused by HOTAIR depletion. In addition, knockdown of MDM4 in H9c2 cells overexpressing HOTAIR was found to result in a decrease in cell viability and increase in apoptosis. These results indicated that HOTAIR inhibited $\mathrm{H}_{2} \mathrm{O}_{2}$-induced apoptosis of $\mathrm{H} 9 \mathrm{c} 2$ cells via the miR-130a-3p/MDM4 axis. He and Jiang (25) previously found that HOTAIR-induced apoptosis is mediated by sponging miR-130a-3p to repress chondrocyte autophagy in knee osteoarthritis.

However, there are a few limitations of the present study. Firstly, the conclusions of this study have not been confirmed by conducting in vivo studies. Secondly, MDM4 could have other roles in ischemic cardiomyopathy, which needs to be studied further. Finally, the specific role of lncRNA HOTAIR in the cells has not been confirmed in this study. In summary, 
A

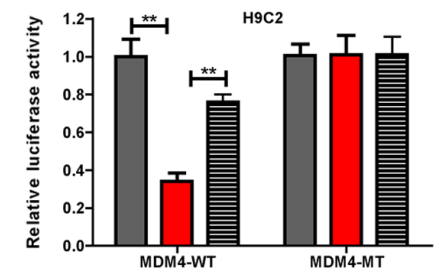

D

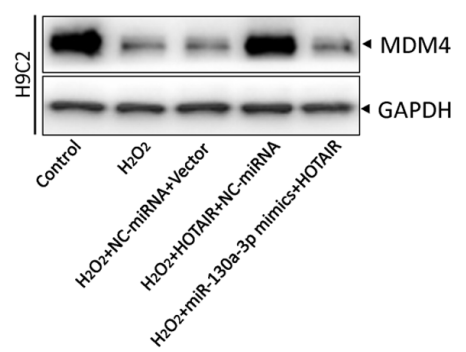

H

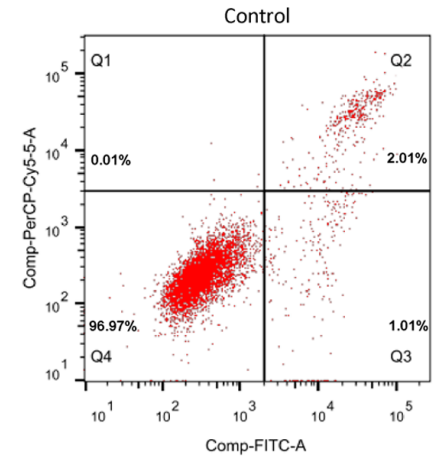

$\mathrm{H}_{2} \mathrm{O}_{2}+$ shControl+HOTAIR

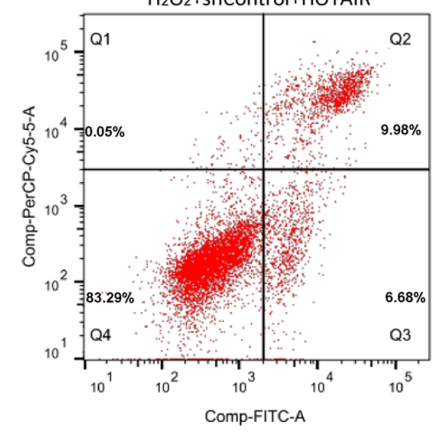

।

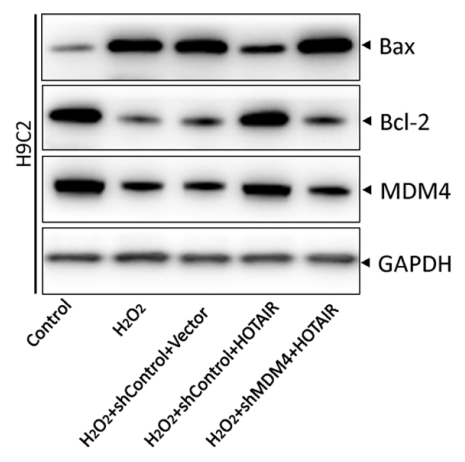

E
口 NC-mirNA

口iR-130a-3p mimics

miR-130a-3p mimics+HOTAIR
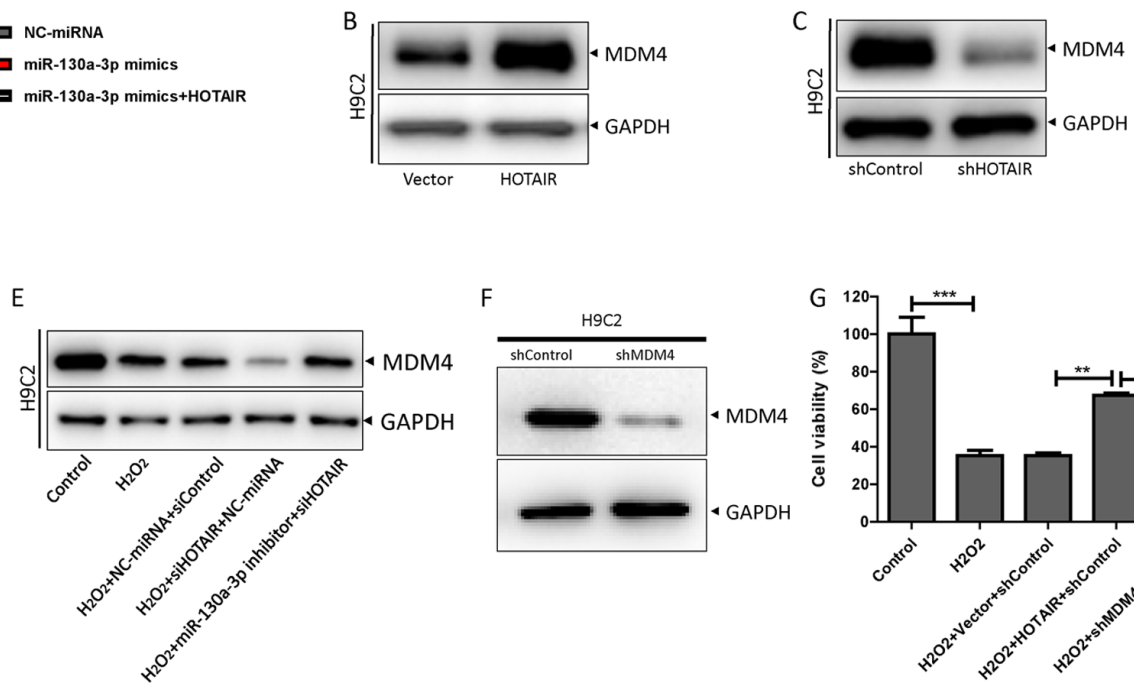

F
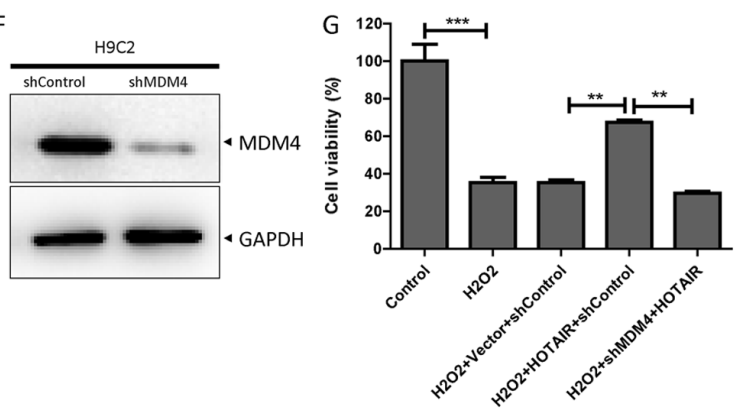

$\mathrm{H}_{2} \mathrm{O}_{2}$
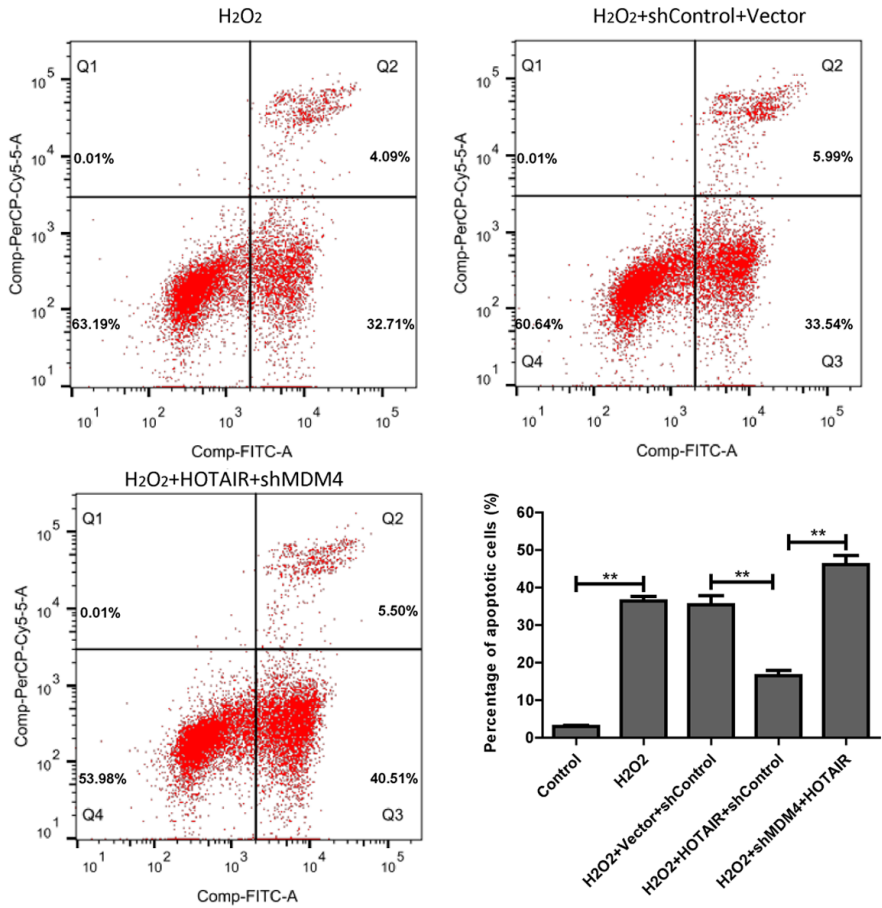

Figure 6. HOTAIR inhibits $\mathrm{H}_{2} \mathrm{O}_{2}$-induced $\mathrm{H} 9 \mathrm{c} 2$ cell apoptosis via the miR-130a-3p/MDM4 axis. (A) The luciferase reporter gene detection system was performed to detect luciferase activity after co-transfection of MDM4-WT or -MT reporter plasmids with miR-130a-3p mimics and HOTAIR for $48 \mathrm{~h}$ according to the manufacturer's instructions. (B) HOTAIR overexpression plasmid or control plasmid was transfected into H9c2 cells, and MDM4 expression was detected by western blotting. (C) shHOTAIR or shControl was transfected into H9c2 cells, and MDM4 expression was detected by western blotting. (D) Scramble or miR-130a-3p mimics were transfected into H9c2 cells with HOTAIR and control plasmids according to the manufacturer's instructions. H9c2 cardiomyocytes were treated with $\mathrm{H}_{2} \mathrm{O}_{2}$ for $12 \mathrm{~h}$, and MDM4 protein expression was detected by western blotting. (E) Scramble or miR-130a-3p inhibitor was transfected into $\mathrm{H} 9 \mathrm{c} 2$ cells with shHOTAIR or shControl, according to the manufacturer's instructions, $\mathrm{H} 9 \mathrm{c} 2$ cardiomyocytes were treated with $\mathrm{H}_{2} \mathrm{O}_{2}$ for $12 \mathrm{~h}$, and MDM4 protein expression was detected by western blotting. (F) After $48 \mathrm{~h}$ of transfection of shMDM4 or shControl into H9C 2 cells, western blotting was used to detect the expression of MDM4 protein. (G) HOTAIR and its control plasmid were co-transfected with shHOTAIR or shControl into H9c2 cells according to the manufacturer's instructions, H9c2 cardiomyocytes were treated with $\mathrm{H}_{2} \mathrm{O}_{2}$ for $12 \mathrm{~h}$, and the cell viability was detected by a Cell Counting Kit- 8 assay. $(\mathrm{H})$ The apoptosis rate was determined by flow cytometry. (I) The expression levels of MDM4, Bcl-2 and Bax protein were detected by western blotting. ${ }^{* *} \mathrm{P}<0.01$ and ${ }^{* * * *} \mathrm{P}<0.001$. MDM4, mouse double minute 4 ; HOTAIR, HOX transcript antisense intergenic RNA; WT, wild-type; miR, microRNA; sh-, short hairpin RNA; MT, mutant. 
the present study demonstrated that the IncRNA HOTAIR inhibited the apoptosis of $\mathrm{H} 9 \mathrm{c} 2$ cells induced by $\mathrm{H}_{2} \mathrm{O}_{2}$ through the miR-130a-3p/MDM4 axis. This study provides a novel direction for prevention and treatment of ischemic cardiomyopathy.

\section{Acknowledgements}

Not applicable.

\section{Funding}

This work was supported by grants from the Natural Science Foundation of Zhejiang Province (grant. no. LY18H270008)

\section{Availability of data and materials}

The datasets used and/or analyzed during the current study are available from the corresponding author on reasonable request.

\section{Authors' contributions}

JF, WZ and PH and JW acquired the data, conducted the formal analysis and utilized the software used in the study. JF also developed the methodology, and wrote the original draft. WZ, JW and PH also assisted with the visualization of the data and study. JW conducted the initial funding acquisition, provided resources and supervision, and helped to review and edit the manuscript. All authors read and approved the final manuscript.

\section{Ethics approval and consent to participate}

All rat experiments conform to the National Institutes of Health Guidelines on the Use of Laboratory Animals and were approved by The First People's Hospital of Tonglu (approval no. 20190154; Hangzhou, China).

\section{Patient consent for publication}

Not applicable.

\section{Competing interests}

The authors declare that they have no competing interests.

\section{References}

1. Muñoz D, Uzoije P, Reynolds C, Miller R, Walkley D, Pappalardo S, Tousey P, Munro H, Gonzales H, Song W, et al: Polypill for cardiovascular disease prevention in an underserved population. N Engl J Med 381: 1114-1123, 2019.

2. Chouchani ET, Pell VR, James AM, Work LM, Saeb-Parsy K, Frezza C, Krieg T and Murphy MP: A Unifying mechanism for mitochondrial superoxide production during ischemia-reperfusion injury. Cell Metab 23: 254-263, 2016.

3. Yan K, An T, Zhai M, Huang Y, Wang Q, Wang Y, Zhang R, Wang T, Liu J, Zhang Y, et al: Mitochondrial miR-762 regulates apoptosis and myocardial infarction by impairing ND2. Cell Death Dis 10: 500, 2019.

4. Li M, Ding W, Tariq MA, Chang W, Zhang X, Xu W, Hou L, Wang $\mathrm{Y}$ and Wang $\mathrm{J}$ : A circular transcript of ncx1 gene mediates ischemic myocardial injury by targeting miR-133a-3p. Theranostics 8: 5855-5869, 2018.
5. Engreitz JM, Ollikainen N and Guttman M: Long non-coding RNAs: Spatial amplifiers that control nuclear structure and gene expression. Nat Rev Mol Cell Biol 17: 756-770, 2016.

6. Chen CK, Blanco M, Jackson C, Aznauryan E, Ollikainen N, Surka C, Chow A, Cerase A, McDonel P and Guttman M: Xist recruits the $\mathrm{X}$ chromosome to the nuclear lamina to enable chromosome-wide silencing. Science 354: 468-472, 2016.

7. Quinn JJ and Chang HY: Unique features of long non-coding RNA biogenesis and function. Nat Rev Genet 17: 47-62, 2016.

8. Sun M, Nie F, Wang Y, Zhang Z, Hou J, He D, Xie M, Xu L, De W, Wang Z, et al: LncRNA HOXA11-AS promotes proliferation and invasion of gastric cancer by scaffolding the chromatin modification factors PRC2, LSD1, and DNMT1. Cancer Res 76: 6299-6310, 2016

9. Chi Y, Wang D, Wang J, Yu W and Yang J: Long non-coding RNA in the pathogenesis of cancers. Cells 8: 1015, 2019.

10. Adams BD, Parsons C, Walker L, Zhang WC and Slack FJ: Targeting noncoding RNAs in disease. J Clin Invest 127: 761-771, 2017.

11. Wei R, Zhang L, Hu W, Wu J and Zhang W: Long non-coding RNA AK038897 aggravates cerebral ischemia/reperfusion injury via acting as a ceRNA for miR-26a-5p to target DAPK1. Exp Neurol 314: 100-110, 2019.

12. Cai B, Ma W, Ding F, Zhang L, Huang Q, Wang X, Hua B, Xu J, Li J, Bi C, et al: The long noncoding RNA CAREL controls cardiac regeneration. J Am Coll Cardiol 72: 534-550, 2018.

13. Ponnusamy M, Liu F, Zhang YH, Li RB, Zhai M, Liu F, Zhou LY, Liu CY, Yan KW, Dong YH, et al: The long non-coding RNA $\mathrm{CPR}$ regulates cardiomyocyte proliferation and cardiac repair. Circulation 139: 2668-2684, 2019

14. Liang H, Su X, Wu Q, Shan H, Lv L, Yu T, Zhao X, Sun J, Yang R, Zhang L, et al: LncRNA 2810403D21Rik/Mirf promotes ischemic myocardial injury by regulating autophagy through targeting Mir26a. Autophagy 16: 1077-1091, 2020.

15. Yin Y, Guan Y, Duan J, Guo Wei, Zhu Y, Quan W, Guo C, Zhou D, Wang Y, Xi M, et al: Cardioprotective effect of Danshensu against myocardial ischemia/reperfusion injury and inhibits apoptosis of H9c2 cardiomyocytes via Akt and ERK1/2 phosphorylation. Eur J Pharmacol 699: 219-226, 2013.

16. Wang JX, Zhang XJ, Li Q, Wang K, Wang Y, Jiao JQ, Feng C, Teng S, Zhou LY, Gong Y, et al: MicroRNA-103/107 regulate programmed necrosis and myocardial ischemia/reperfusion injury through targeting FADD. Circ Res 117: 352-363, 2015.

17. Khoo CM and Tai ES: Trends in the incidence and mortality of coronary heart disease in asian pacific region: the Singapore experience. J Atheroscler Thromb 21 (Suppl 1): S2-S8, 2014.

18. Dalen JE, Alpert JS, Goldberg RJ and Weinstein RS: The epidemic of the 20(th) century: Coronary heart disease. Am J Med 127: 807-812, 2014.

19. Mauermann E, Puelacher C and Lurati Buse G: Myocardial injury after noncardiac surgery: An underappreciated problem and current challenges. Curr Opin Anaesthesiol 29: 403-412, 2016.

20. Heusch G and Gersh BJ: The pathophysiology of acute myocardial infarction and strategies of protection beyond reperfusion: A continual challenge. Eur Heart J 38: 774-784, 2017.

21. Zhang D, Wang B, Ma M, Yu K, Zhang Q and Zhang X: lncRNA HOTAIR Protects Myocardial Infarction Rat by Sponging miR519d-3p. J Cardiovasc Transl Res, 12 (3): 171-183, 2019.

22. Li X, Wang H, Yao B, Xu W, Chen J and Zhou X: IncRNA H19/ miR-675 axis regulates cardiomyocyte apoptosis by targeting VDAC1 in diabetic cardiomyopathy. Sci Rep 6: 36340, 2016.

23. Wang Y, Du J, Niu X, Fu N, Wang R, Zhang Y, Zhao S, Sun D and Nan Y: MiR-130a-3p attenuates activation and induces apoptosis of hepatic stellate cells in nonalcoholic fibrosing steatohepatitis by directly targeting TGFBR1 and TGFBR2. Cell Death Dis 8: e2792, 2017.

24. Chen X, Yue B, Zhang C, Qi M, Qiu J, Wang Y and Chen J: MiR-130a-3p inhibits the viability, proliferation, invasion, and cell cycle, and promotes apoptosis of nasopharyngeal carcinoma cells by suppressing BACH2 expression. Biosci Rep 37: BSR20160576, 2017.

25. He B and Jiang D: HOTAIR-induced apoptosis is mediated by sponging miR-130a-3p to repress chondrocyte autophagy in knee osteoarthritis. Cell Biol Int 44: 524-535, 2020. 